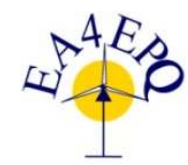

International Conference on Renewable Energies and Power Quality (ICREPQ'14)

Cordoba (Spain), $8^{\text {th }}$ to $10^{\text {th }}$ April, 2014

Renewable Energy and Pourer (Duality. Fourna(RE\&PQJ)

ISSN 2172-038 X, No.12, April 2014

\title{
Optimization of copper in a renewable source based network
}

\author{
${ }^{1}$ Si Ali.M, ${ }^{1}$ Fergani.S, ${ }^{1}$ Flazi.S and ${ }^{2}$ BoudgheneStambouli.A \\ ${ }^{1}$ Department of Electrical Engineering, \\ Phone numbre : +00213 778428 023, e-mail: m.siali.teme2@ @otmail.fr,fergani.samia@ hotmail.fr, flazis@ yahoo.fr, \\ ${ }^{2}$ Department of Electronic, \\ E-mail: aboudghenes@gmail.com \\ University of Sciences and Technology of Oran Mohamed Boudiaf (USTO-MB)
}

\begin{abstract}
The objective of this work is to find the optimal location for installing the generator to allow minimizes cable prices by optimizing the volume of used copper. One approach to solving the problem presented here is to determine the point where we need to insert the generator, such that the volume of copper is reduced. This position is called the gravity center of the charges "GCC".

The method used in this paper is comparable to the determination of the gravity center of a system made up of points weighted with the power ratings of the various electrical loads. [1]In order to show that the gravity center gives us a minimum volume of copper, it is required:
\end{abstract}

- First, a change in the position of generator from a point $\mathrm{O}$ $(0,0)$ and

- Second a load position scanning across the surface.

The use of MATLAB software has helped us to verify and confirm the result.

\section{Key words}

Electrical gravity center, photovoltaic grid, distribution grid optimization, grid topology.

\section{Introduction}

Increased electrification needs, in the world, have created a new market for the industry. And solar energy has been a very important development that has allowed it to be an essential component of the modern economy.

Solar photovoltaic installations provide power to the isolated electrical grid systems. There are two types of PV system:

-Installations connected to the network.

-Autonomous installations.

Design, optimization and implementation of photovoltaic systems are topical problems. They surely lead to a better use of solar energy.[2]
One of these problems is the point where must be placed the photovoltaic generator relative to the loads.

The network should be optimized to minimize operating costs of installation. For that we will try to answer questions that arise and which are:

How to build and maintain the network at a lower cost?

The position of the PV generator minimizes the installation cost. How can we get this position? And what is its influence on the minimization of the cost?

The determination of the gravity center is very widespread in the calculations and dimensioning of electrical grid, but its physical meaning and its influence on the network topology is not very well known.

The aim of our work is to find the physical explanation of the electrical gravity center and to use it in the optimization of an electrical grid supplied by solar generators.

\section{Mechanical gravity center}

A. The mechanical moment [3]

\section{1) Physical definition}

The moment of a force is a physical phenomenon which causes the rotation or stopping of the rotation or twisting of a piece.

\section{2) Calculation of the moment}

- Using the lever arm

$$
\left\|\overrightarrow{\mathrm{M}_{\mathrm{A}}(\mathrm{F})}\right\|=\|\overrightarrow{\mathrm{F}}\| \cdot \mathrm{d}
$$

$\left\|\overrightarrow{\mathrm{M}_{\mathrm{A}}} \overrightarrow{(\mathrm{F})}\right\|:$ The moment's module (N.m),

$\|\overrightarrow{\mathrm{F}}\|$ : The module of the force $(\mathrm{N})$,

$\mathrm{d}: \operatorname{Distance}(\mathrm{m})$. 
Recall that for a solid balance:

$$
\sum_{i=1}^{n} \overrightarrow{M_{A}}\left(\overrightarrow{F_{1}}\right)=\overrightarrow{0}
$$

\section{B. The mechanic gravity center}

In physics, the gravity center is the application of the resultant force of gravity or gravity points. Thus, it is clearly dependent on the gravitational field in which the body is subjected. [4]

In Static, the gravity center is the application's point of weight.

\section{Calculating the position of gravity center}

$$
\mathrm{p}_{\mathrm{tot}}=\sum_{\mathrm{i}}^{\mathrm{n}} \mathrm{p}_{\mathrm{i}}
$$

$\mathrm{p}$ : Weight $(\mathrm{kg})$

$$
\mathrm{M}_{\mathrm{tot}}^{\mathrm{o}}=\sum_{\mathrm{i}}^{\mathrm{n}} \mathrm{x}_{\mathrm{i}} \mathrm{p}_{\mathrm{i}}^{\mathrm{o}}
$$

$\mathrm{M}_{\mathrm{tot}}^{\mathrm{o}}$ : Total moment from the point $\mathrm{O}$.

The sum of moments at GC is zero.

$$
\mathrm{x}_{\mathrm{CG}}=\frac{\sum_{\mathrm{i}}^{\mathrm{n}} \mathrm{x}_{\mathrm{i}} \mathrm{p}_{\mathrm{i}}^{\mathrm{o}}}{\sum_{\mathrm{i}}^{\mathrm{n}} \mathrm{p}_{\mathrm{i}}}
$$

$\mathrm{x}_{\mathrm{CG}}$ : Position of gravity center.

The gravity center position in space: [5]

$$
\mathbf{x}_{\mathbf{C G}}=\frac{\sum_{\mathrm{i}}^{\mathbf{n}} \mathbf{x}_{\mathbf{i}} \mathbf{p}_{\mathbf{i}}^{\mathbf{o}}}{\sum_{\mathrm{i}}^{\mathbf{n}} \mathbf{p}_{\mathbf{i}}} ; \mathbf{y}_{\mathbf{C G}}=\frac{\sum_{\mathrm{i}}^{\mathbf{n}} \mathbf{y}_{\mathrm{i}} \mathbf{p}_{\mathrm{i}}^{\mathbf{o}}}{\sum_{\mathrm{i}}^{\mathbf{n}} \mathbf{p}_{\mathrm{i}}} ; \mathbf{z}_{\mathbf{C G}}=\frac{\sum_{\mathrm{i}}^{\mathbf{n}} \mathbf{z}_{\mathrm{i}} \mathbf{p}_{\mathrm{i}}^{\mathbf{o}}}{\sum_{\mathrm{i}}^{\mathbf{n}} \mathbf{p}_{\mathbf{i}}} \text { (6), }
$$

\section{Electrical gravity Center}

In the case of electrical moment, we replaced the weight by the electrical power and found:

$$
\mathrm{M}_{\mathrm{e} . \mathrm{tot}}=\sum_{\mathrm{i}}^{\mathrm{n}} \mathrm{x}_{\mathrm{i}} \cdot \mathrm{p}_{\mathrm{i}}
$$

Where:

$\mathrm{M}_{\mathrm{e}}$ being the electric moment (m.A) for a group of charges in which the Cartesian coordinates of each load are known.

At The gravity center, we have:

$$
\sum_{\mathrm{i}}^{\mathrm{n}} \overrightarrow{\mathrm{M}_{\mathrm{e}}}=\overrightarrow{0}
$$

The Calculation and design of the electrical network in the plane $(x, y)$ is given by:

$$
\Rightarrow\left\{\begin{array}{l}
\sum_{\mathrm{i}}^{\mathrm{n}}\left(\mathrm{x}_{\mathrm{i}}-\mathrm{x}_{\mathrm{CG}}\right) \mathrm{p}_{\mathrm{i}}=0 \\
\sum_{\mathrm{i}}^{\mathrm{n}}\left(\mathrm{y}_{\mathrm{i}}-\mathrm{y}_{\mathrm{CG}}\right) \mathrm{p}_{\mathrm{i}}=0
\end{array}\right.
$$

We will therefore have

$$
\begin{aligned}
\mathrm{x}_{\mathrm{CG}} & =\frac{\sum_{\mathrm{i}}^{\mathrm{n}} \mathrm{x}_{\mathrm{i}} \mathrm{p}_{\mathrm{i}}}{\sum_{\mathrm{i}}^{\mathrm{n}} \mathrm{p}_{\mathrm{i}}} \\
\mathrm{y}_{\mathrm{CG}} & =\frac{\sum_{\mathrm{i}}^{\mathrm{n}} \mathrm{y}_{\mathrm{i}} \mathrm{p}_{\mathrm{i}}}{\sum_{\mathrm{i}}^{\mathrm{n}} \mathrm{p}_{\mathrm{i}}}
\end{aligned}
$$

$\left(\mathrm{X}_{\mathrm{CG}}, \mathrm{Y}_{\mathrm{CG}}\right)$ electrical gravity's center position, $\left(\mathrm{X}_{\mathrm{i}}, \mathrm{Y}_{\mathrm{i}}\right)$ : the position of $i^{\text {th }}$ charge in the site, $n$ the number of loads established on the site and $\mathrm{P}$ represents the consumption by the $i^{\text {th }}$ charge.

If we consider that the voltage is constant and all charges have the same number of phases, we can write:

$$
\mathrm{M}_{\mathrm{e}}=1 \cdot \mathrm{p} \rightarrow \mathrm{M}_{\mathrm{e}} \approx 1 \cdot \mathrm{u} . \mathrm{I}
$$

I: the current value (A), u:the voltage (V).

$$
M_{e . t o t}=\sum_{i}^{n} l_{i} I_{i}
$$

\section{Physical meaning of gravity center}

To understand the physical meaning of the gravity center and show its importance, we have performed several calculations of many examples using MATLAB, to see the influence of generator's position on the volume of copper and electrical losses in the cables, because these two parameters are needed to optimize the cost of a network.

The volume of copper used can be calculated by the following equation:

$$
\mathrm{V}_{\mathrm{i}}=\mathrm{s}_{\mathrm{i}} \cdot \mathrm{l}_{\mathrm{i}}
$$

Where $V_{i}$ represent the volume of copper used in the $i^{\text {th }}$ cable.

Joule losses in the cables are calculated using the equation (17) [7]:

$$
P_{i}=R_{i} I_{i}^{2}=\frac{l_{i} \cdot \rho \cdot I_{i}^{2}}{s_{i}}
$$

Where $\mathrm{P}_{\mathrm{i}}$ represent joule losses of the $\mathrm{i}^{\text {th }}$ cable (Watt). $\mathrm{R}_{\mathrm{i}}$ being the electrical cable's resistance.

The equation (18) is used to calculate the length of the cables connecting the load with the supply power:

$$
\mathrm{l}_{\mathrm{i}}=\left(\left(\mathrm{x}_{\mathrm{i}}-\mathrm{x}_{\mathrm{CG}}\right)^{2}+\left(\mathrm{y}_{\mathrm{i}}-\mathrm{y}_{\mathrm{CG}}\right)^{2}\right)^{1 / 2}
$$

For a maximum voltage drop authorized, the cross section of each cable connected to the solar generator is given by the equation (19) [6]:

$$
s_{i}=\frac{\sqrt{3}}{\Delta u} \rho \cdot \cos \varphi \cdot I_{i} \cdot l_{i}
$$


Where:

$\Delta u$ is the maximum voltage drop authorized.

Regarding copper material where $\rho=22.5 \Omega . \mathrm{m}$,

\section{A- The calculation method}

We have calculated the length, cross section, volume of copper and losses, using all the generator's positions covering the entire surface limited by the electrical loads, to demonstrate that the smallest volume of copper is at the gravity center. We found that the gravity center position corresponds to the minimum copper volume.

The calculation method is presented in the following flowchart:

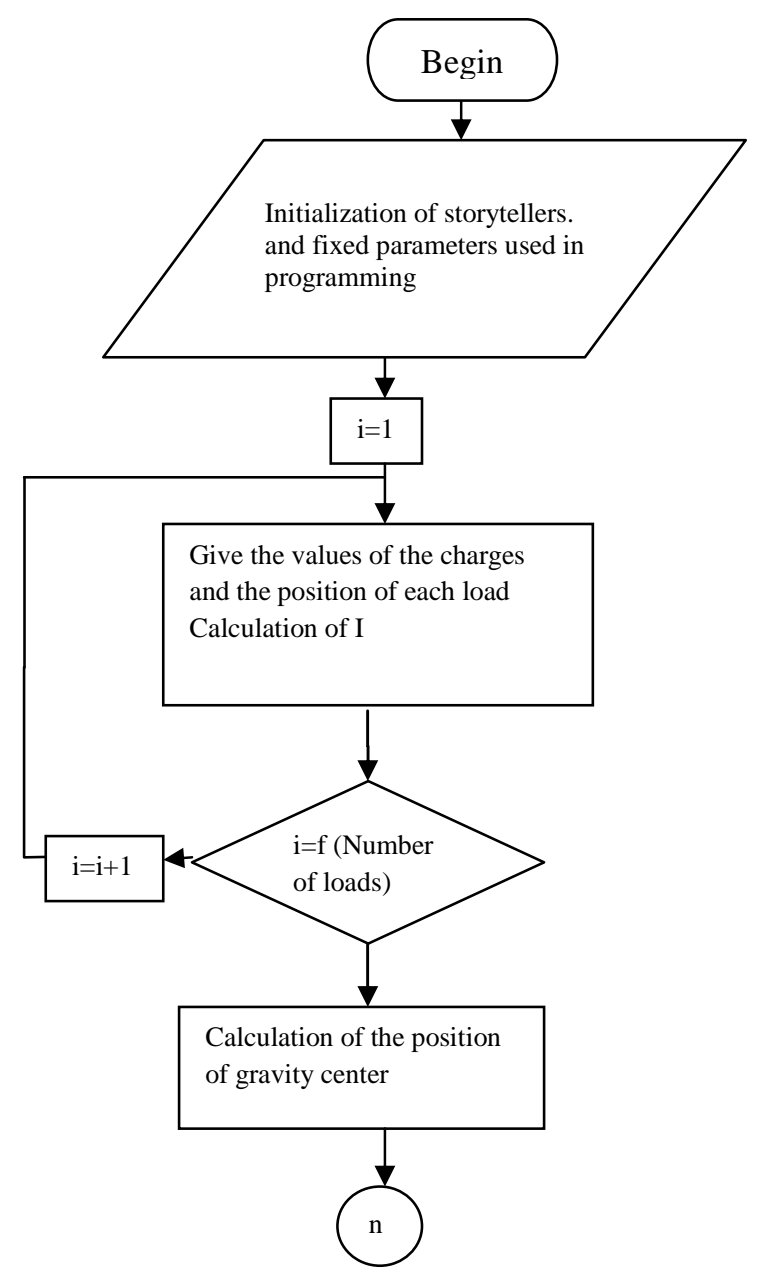


The Examples treated using MATLAB programming, confirm that the quantity of copper is optimal at the gravity center.

\section{B- Example of calculation}

Among the treated examples, we present a site of five loads.
Table 1contains: the power of each load is represented in the first column, the $\mathrm{x}$ and $\mathrm{y}$ position's loads in columns 3 and 4, the position of gravity center in column 5 and 6 , the minimum volume of copper in column 9 , the value of the maximum volume in column 10 and its position in the column 11 and 12.

Tab.1.Calculated lengths, cross sections, volume of copper after optimization of solar generator position

\begin{tabular}{|c|c|c|c|c|c|c|c|c|c|c|c|c|}
\hline $\mathrm{P}(\mathrm{w})$ & $\mathrm{I}(\mathrm{A})$ & $\mathrm{X}(\mathrm{km})$ & $\mathrm{Y}(\mathrm{km})$ & $\mathrm{X} 0(\mathrm{~km})$ & $\mathrm{Y} 0(\mathrm{~km})$ & $\mathrm{L}(\mathrm{km})$ & $\mathrm{s}\left(\mathrm{mm}^{2}\right)$ & $\mathrm{V}_{\min }\left(10^{4} \mathrm{~cm} 3\right)$ & $V_{\max }\left(10^{4} \mathrm{~cm}^{3}\right)$ & $X_{\max }(\mathrm{km})$ & $Y_{\max }(\mathrm{km})$ & $\cos$ \\
\hline 32000 & 46.243 & 0.055 & 0.55 & \multirow{5}{*}{0.317} & \multirow{5}{*}{0.297} & 0.364 & 49.53 & \multirow{5}{*}{3.5615} & \multirow{5}{*}{13.2239} & \multirow{5}{*}{0.000} & \multirow{5}{*}{0.000} & \multirow{5}{*}{0.8} \\
\hline 37000 & 53.468 & 0.505 & 0.055 & & & 0.306 & 47.912 & & & & & \\
\hline 18000 & 26.012 & 0.505 & 0.505 & & & 0.279 & 19.868 & & & & & \\
\hline 24000 & 34.682 & 0.305 & 0.285 & & & 0.017 & 1.612 & & & & & \\
\hline 25000 & 36.127 & 0.255 & 0.195 & & & 0.12 & 11.61 & & & & & \\
\hline
\end{tabular}

In this example, we found that at the center of gravity, the volume of copper was minimum, and the maximum volume was in the position $(0,0)$, a reduction of approximately $26 \%$ of copper volume, used in cables, is then estimated.

\section{Conclusion}

The results show that the gravity center position is optimal from the standpoint copper volume that minimizes the fixed cost of network. The position of the solar generator is therefore found.

$>$ In this position, a very significant reduction of copper used is found which allows to reduce the price of cables

$>$ But to win on the economy savings and energy efficiency, we must balance the costs of joule losses and copper used in cables, while the gravity center does not meet to minimum losses, because the cross sections calculated are a minimum for each cable that gives us very great losses. The sections can be increased to optimize losses, but in order to keep the copper volume reasonable. It is the study of our group that may be presented at the same conference.
So we must look for the most optimized total cost of copper volume and the losses, keeping the position of generator in the gravity center.

\section{References}

[1]R.Tchuidjan, O.Hamandjoda, M.Tabe « réduction des pertes de puissance dans un réseau de distribution alimenté par un générateur d'énergie nouvelle et renouvelable ».Revue des énergies renouvelable. Vol 141 $\mathrm{N}^{\circ} 3(2011) 449-459$.

[2] K.Kassim, M.Hamdaoui et F.Olivié «conception et modélisation d'un système photovoltaïque adapté par une commande MPPT analogique». Revue des énergies renouvelable. Vol.10 N4(2007) 451-462.

[3] http://noel.wifeo.com/documents/Cours-statique.pdf

[4] http://fr.wikipedia.org/wiki/Centre_de_gravit\%C3\%A9

[5]https://cours.etsmtl.ca/seg/mperrault/presentations/ing120/ch-05\%20centre\%20de\%20gravite.PDF

[6] ouvrage réalisé par un groupe animé par Gérard SOLIGNAC, «guide de l'ingénierie électrique des réseaux internes d'usines », ISBN 2-85206-311-5, deuxième tirage revu juin 1986.ch.9.pp19.

[7] Olivier Vourgeois, Hervé Guillou, «conduction électrique dans le solide- introduction et théorie élémentaire », technique de l'ingénieur, référence D 2601, 7200092269,2013 